\title{
Analisa Debit Andalan Pada Das Batang Arau Dengan Menggunakan Model Soil And Water Assessment Tool (SWAT)
}

\section{Mainstay Discharge Analysis at The Bottom of the Stem Using the Soil Water Assessment Tool ( SWAT )}

\author{
Maryam Afifa, Afla Dina, Elvi Roza Syofyan \& Wisafri \\ Jurusan Teknik Sipil Politeknik Negeri Padang Kampus Limau Manis Padang 25163 \\ Telp. 0751-72590 Fax. 0751-72576 Email : afifamaryam19@gmail.com, \\ afladina1797@gmail.com, syofyan_er@yahoo.co.id
}

\section{ABSTRACT}

Batang Arau is one of the rivers that flows in the city of Padang, the upstream part of the Batang Arau watershed starting from the Lubuk Paraku river which is in the northeast of Padang City, with a water catchment area of 2,504 hectares which is Dr. Muhammad Hatta, Nature Reserve Area Barisan I and Arau downstream. The Batang Arau watershed has decreased its primary forest area due to the large number of additional settlements. The increase in residential area resulted in the land that was previously not waterproof. The mainstay discharge always increases in the rainy season and decreases in the dry season. The mainstay discharge in the Batang Arau watershed is calculated using the Fj Mock method. The Batang Arau watershed also knows the mainstay discharge that occurred in 2010, 2012 and 2018 using the Soil and Water Assessment Tool (SWAT) model. The analysis was obtained from four processes, namely delineation of the watershed, the formation of the Hydrologic Response Unit (HRU), the formation of climatological data, and the simulation process. For the HRU analysis of the Batang Arau watershed, it was obtained 7 sub-watersheds, the dominant $H R U$, namely primary dryland forest, was $74.68 \%$.

Keywords: Land use, SWAT, HRU, Mainstay discharge

\section{PENDAHULUAN}

Perencanaan suatu lahan sangat berpengaruh terhadap karakteristik hidrologi suatu DAS. Secara geografis, DAS Batang Arau terletak pada 0' 48' sampai dengan 0' 56' $S$ dan 100' 021' sampai dengan 100' 33' BT dengan ketinggian 0 sampai dengan $1.210 \mathrm{~m}$ dari permukaan laut (dpl). ( BAPEDAS Kota Padang ).

DAS sangat berpengaruh terhadap kebutuhan air baku disuatu daerah. Air baku merupakan air yang dibutuhkan dalam proses produksi maupun air untuk kebutuhan sehari-hari yang pada umumnya berasal dari air hujan, air danau, air tanah, dan air sungai (Rau, 2012).

Daerah bagian hulu DAS Batang Arau digunakan sebagai daerah konservasi tempat penyimpanan dan penyuplai air (bufferzone) bagi wilayah Kota Padang
(Bappeda Kota Padang). DAS Batang Arau terletak di Kota Padang mempunyai luas $174,675 \mathrm{~km}^{2}$ dengan 13 Sub DAS yang mengalir sepanjang Batang Arau. Dalam kurun waktu 10 tahun ini perluasan hutan rakyat / lading petani mengalami peningkatan, hal ini ditandai adanya perubahaan lahan seperti hutan lahan kering sekunder mengalami perubahaan yang cukup besar tahun 2006 (846.09 ha), 2015(2959.65ha),pertanian lahan kering tahun 2006 (0 ha) sedangkan tahun 2015 (1521.98 ha) dan juga pemukiman tahun 2006 (3494.05 ha)sedangkan tahun 2015 (3677.16 ha).

Batang Arau merupakan sungai yang sangat tercemar yang ada dikawasan Kota Padang. Pada bagian hulu sungai merupakan tempat pembuangan limbah dari pabrik semen, pabrik sawit dan pabrik karet. Bagian tengah terdapat limbah 
rumah sakit dan klinik kecil. Pada bagian hilir merupakan tempat pembuangan limbah pasar raya, dan dibagian muara juga menjadi tempat pembuang limbah kapal..

Pada DAS Batang Arau perlu dilakukan perbaikan DAS salah satunya dengan cara pernecanaan tataguna lahan menggunakan beberapa aspek yang sistematik. Hubungan antara penggunaan lahan dan hidrologi dapat dihitung menggunakan suatu model hidrologi. Pemodelan hidrologi dapat menghitung debit andalan yang terdapat dalam suatu Sub DAS Batang Arau.

\section{METODOLOGI}

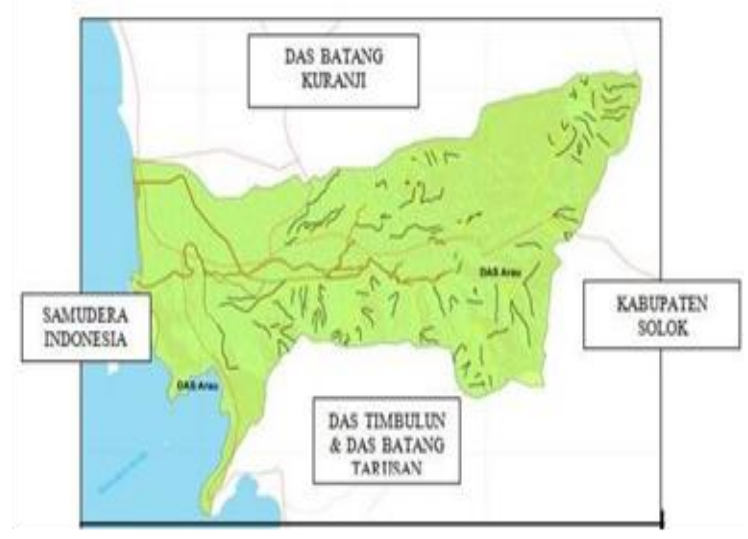

Gambar 1. DAS Batang Arau

Pengumpulan peta dan data dapat dilakukan sebagai pendukung kegiatan penelitian. Peta dikumpulkan paling utama yang mendukung operasional model SWAT.

Data yang dikumpulkan yaitu data primer dan sekunder baik dari data penelitian sebelumnya maupun dari instansi - instansi terkait. Peta dan data yang perlu dikumpulkan terdiri dari data sekunder dan data primer.

a. Pengumpulan Data Sekunder

Pengumpulan data sekunder antara lain :
- Peta dan Data Tanah, yang mana diperoleh dari data Global yang sudah teruji empirisnya.

- DEM 30 x 30 m dari DEMNAS.

- Data Klimatologi stasiun Gunung Nago maksimum dan minimum dari tahun 2009 sampai 2018.

- Data curah hujan harian Stasiun Ladang Padi, Stasiun Gunung Nago dan Stasiun Bungus dari tahun 2009 sampai 2018 dari PSDA Kota Padang.

b. Pengumpulan Data Primer

Pengumpulan data Primer antara lain :.

- Peta penggunaan lahan yang diperoleh dari United States Geological Survey ( USGS ).

\section{Pengolahan Data Input}

Tahapan yang dilakukan adalah :

a. Delineasi daerah Observasi

Dengan menggunakan perangkat lunak MapWindows/MicrosoftNetDapat

dilakukan Proses delineasi menggunakan data DEM SRTM dengan resolusi 30 meter. Daerah observasi akan didelineasi berdasarkan batas topografi alami DAS. Metode yang digunakan dalam proses delineasi adalah metode threshold, yang mana nilai threshold baik besar maupun kecil dapat digunakan untuk menentukan jumlah jaringan sungai yang terbentuk. Jadi, semakin besar nilai threshold yang dimasukkan, maka semakin kecil jumlah jaringan sungai yang terbentuk, begitupun sebaliknya.

b. Pembentukan Hydrologic Response Unit ( HRU )

Pada aplikasi SWAT Wilayah hidrologi dapat dibentuk berdasarkan pembuatan Hydrological Response Unit (HRU). HRU mengambarkan pengaruh suatu wilayah terhadap faktor hidrologi yang terjadi pada wilayah tersebut, pembagian wilayah tersebut berdasarkan karakteristik tanah, tataguna lahan, dan kemiringan lahan. 
Input peta tanah dan penggunaan lahan harus dalam koordinas sitem UTM, dan dalam format raster. Selanjutnya faktor kemiringan yang digunakan dalam menentukan HRU dibagi dalam beberapa pembagian menurut yakni 5, 15, 25, sampai 40. Threshold dari persentase total luasan yang digunakan untuk landuse (10\%), jenis tanah (5\%), dan Slope (5\%) yang memiliki persentase luasan yang lebih kecil dari threshold yang ditentukan untuk diabaikan. (Irsyad, 2011) Model SWAT ini menggunakan Satuan yaitu Satuan Peta Tanah (SPT) yang digunakan untuk menghitung pembagian wilayahnya.

c. Pengabungan HRU dengan data iklim Setelah satuan analisis terbentuk baru dilakukan Proses penggabungan HRU dan data iklim. Pada tahap ini dilakukan periode simulasi terlebih dahulu kemudian baru dilakukan pemasukan data iklim.

Pembuatan basis data iklim dilakukan untuk membuat data generator iklim (weather generator data) terdiri atas 14 parameter input yang harus dihitung terlebih dahulu berdasarkan data iklim. Selain itu juga dibutuhkan pembuatan file input data curah hujan (rainfall data) tahun 2009 hingga 2018 yang berasal dari stasiun pengamatan Bendung Gunung Nago dan data iklim tahun 2009 hingga 2018 berasal dari Stasiun Badan Meteorologi Klimatologi dan Geofisika (BMKG) di Kota Padang. d. Simulasi dan Kalibrasi

Dalam input model SWAT, terdapat 500 parameter yang digunakan dalam simulasi. Tetapi parameter tersebut tidak seluruhnya dapat digunakan karena adanya keterbatasan waktu dan data. Pemilihan parameter yang dominan dilakukan hingga didapatkan hasil yang mendekati kondisi sebenarnya.

e. Parameterisasi Input Simulasi

Parameterisasi yang dilakukan dalam simulasi menggunakan SWAT. Langkah-langkah dalam pengoperasian SWAT adalah sebagai berikut.

1. Setelah program telah dilakukan instalasi, masukkan SWAT TxInOut directory dipilih sebagai sumber data untuk proyek baru.

2. Kemudian pilih satu program kalibrasi yang tersedia (SUFI, GLUE, ParaSol, MCMC).

3. Setelah proyek diberi nama, tentukan lokasi penyimpanan proyek. Diharapkan file tersebut terletak di luar folder yang ada di hardisk agar mudah disimulasikan.

4. Pada tampilan project explorer window terdapat menu masukan kalibrasi yang berisi data parameter yang akan dikalibrasi. Menu kalibrasi tersebut merupakan parameter yang akan diteliti.

5. Setelah nilai parameter diubah, proses kalibrasi dijalankan dengan tombol execute pada tool bar. 
Diagram Alir Penelitian

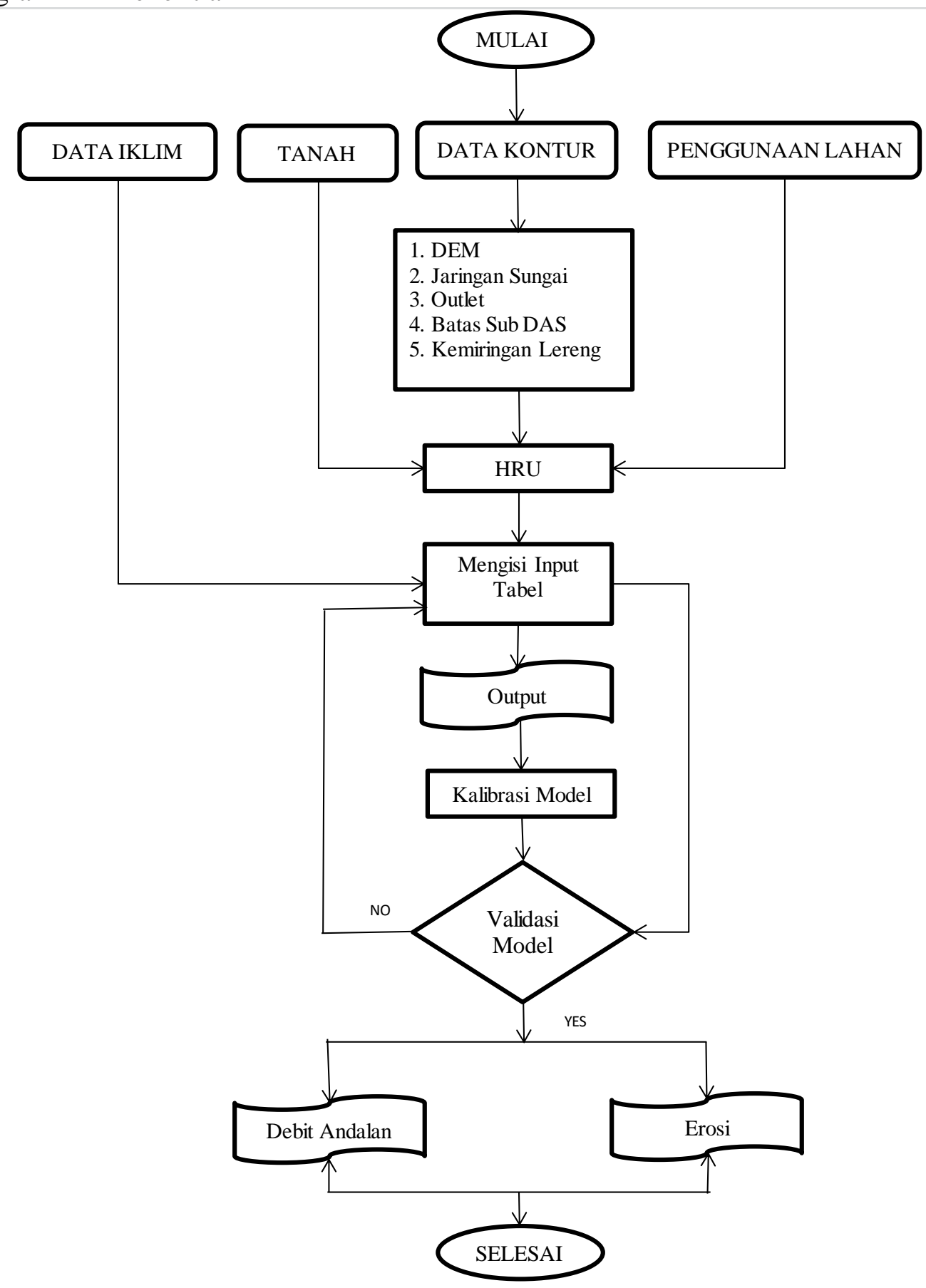

Gambar 2. Diagram Alir Penelitian

\section{HASIL DAN PEMBAHASAN}

\section{Analisa HRU}

Pada analisa HRU, diperoleh kemiringan pada DAS Batang Kuranji dengan level kemiringan sebagai berikut.

- Agak datar : kemiringan 1-3\%

- Agak landai: kemiringan 3-8\%
- Bergelombang : kemiringan 8-15\%

- Berbukit kecil : kemiringan 15-25\%

- Agak curam : kemiringan 16-25\%

- Berbukit : kemiringan $25-40 \%$

- Pegunungan : kemiringan $>40 \%$ 


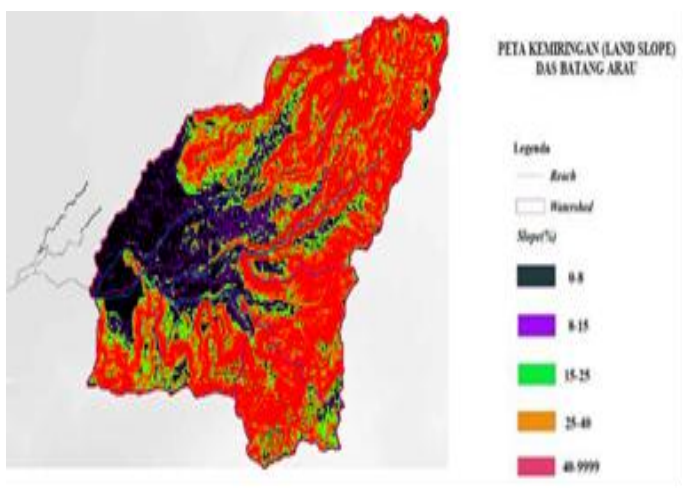

Gambar 3. Kemiringan DAS Batang iArau berdasarkan analisis HRU

Hasil analisis cluster pada DEM SRTM ini diperoleh 7 sub DAS dengan luas area yang bervariasi. Berdasarkan gambar 4 terlihat bahwa subDAS yang mempunyai luas terbesar adalah subDAS $t$ dan yang terkecil adalah subDAS 2 .

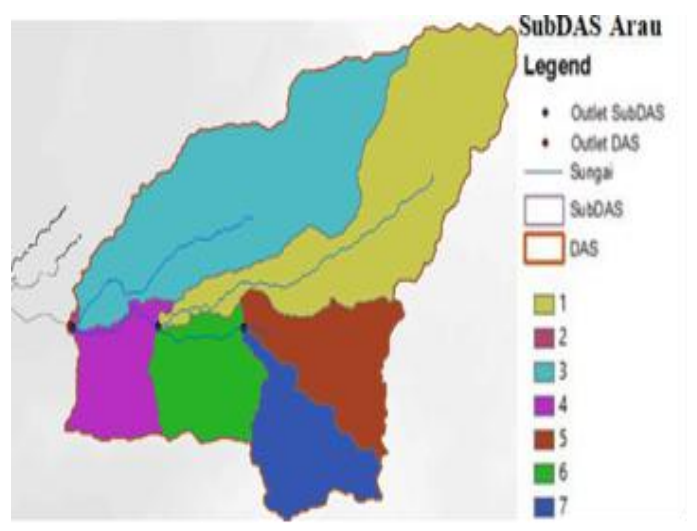

Gambar 4. Peta DAS Batang Arau yang diperoleh berdasarkan analisis cluster DEM SRTM

\section{Klasifikasi Kelas Penggunaan Lahan}

Perubahan Hydrologic Response Unit (HRU) dapat diamati berdasarkan perubahan tutupan lahan, karena HRU merupakan tumpang tindih dari penutup lahan, lereng, dan karakteristik tanah. Perubahan penutup lahan yang terjadi pada suatu wilayah fenomenanya dapat diamati dengan menggunakan citra satelit multi waktu. Selain perubahan penutup lahan secara temporal, jumlah kelas saat klasifikasi juga akan mempengaruhi pola tutupan lahan. Pada penelitian ini digunakan dua tahap klasifikasi penutup lahan di DAS Batang Arau berdasarkan citra Landsat. Pada tahap 2010, 2012, dan 2018 diperoleh 7 klasifikasi tataguna lahan seperti hutan lahan kering primer, hutan lahan kering sekunder, semak belukar rawa, pemungkiman, sawah, pertanian lahan kering, pertanian lahan kering campur semak.

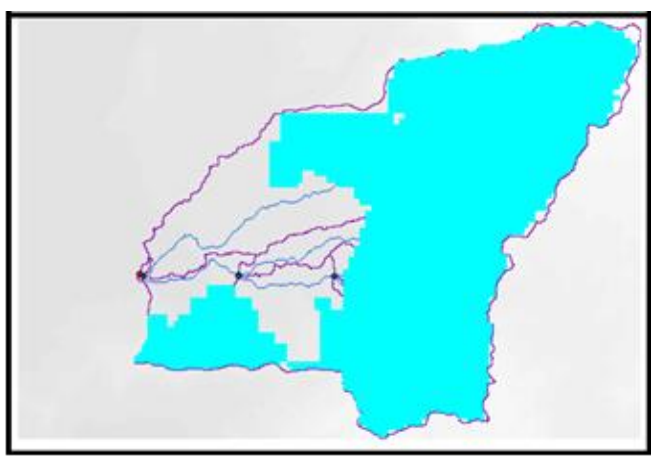

Gambar 5. HRU hutan lahan kering primer

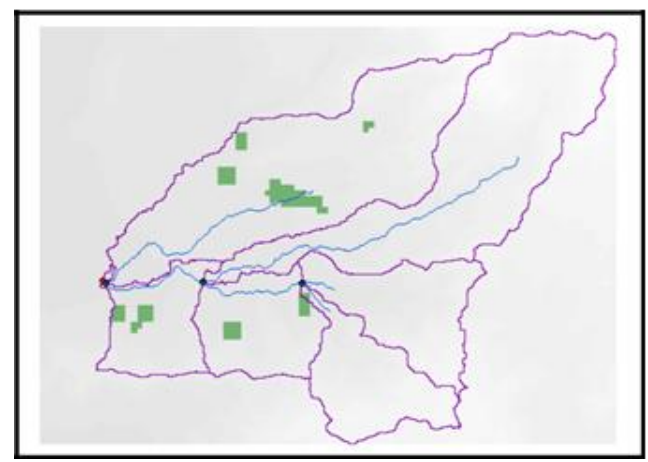

Gambar 6. HRU semak belukar rawa

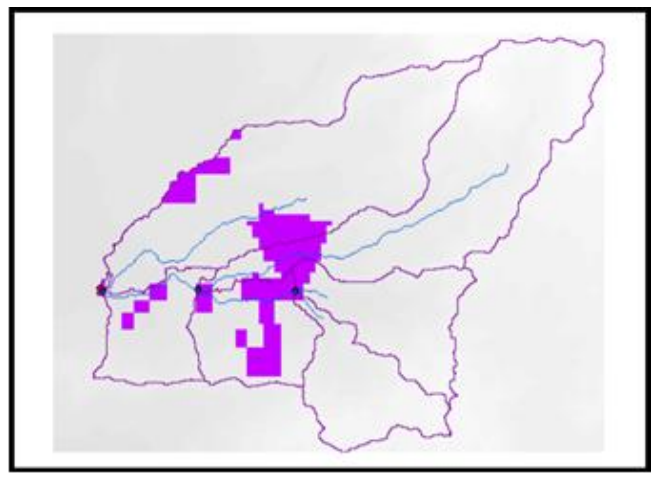

Gambar 7. HRU hutan lahan kering sekunder 


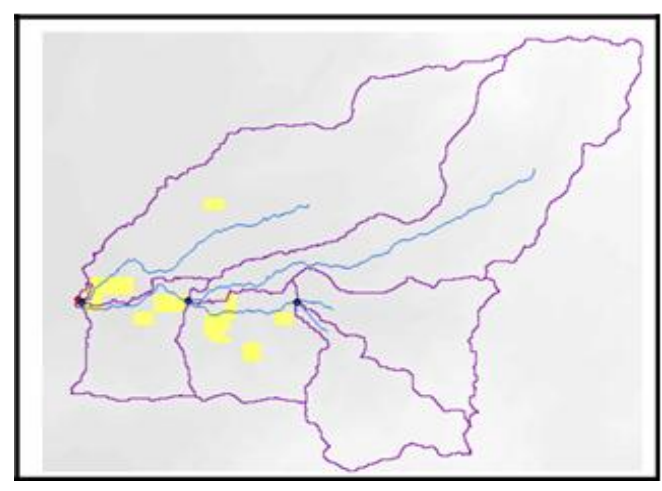

Gambar 8. HRU pemungkiman

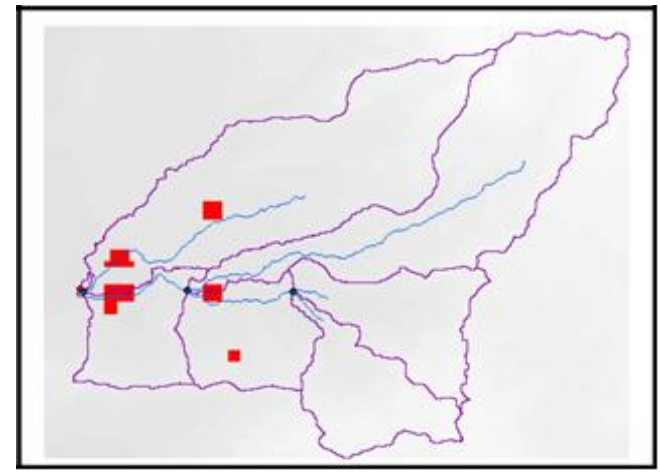

Gambar 9. HRU sawah

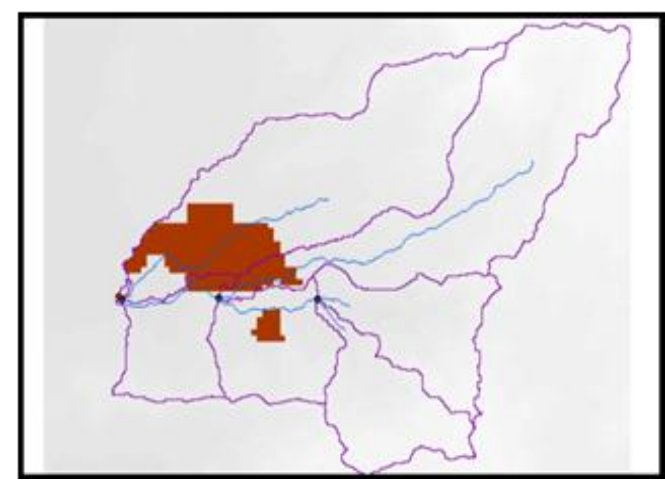

Gambar 10. HRU pertanian lahan kering

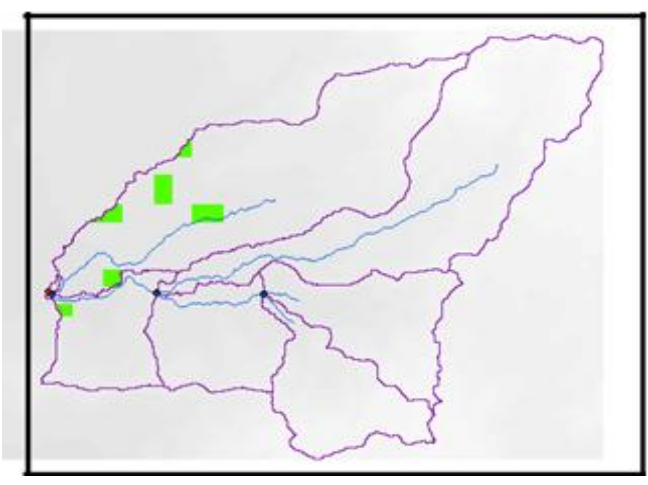

Gambar 11. HRU pertanian lahan kering campur semak
Pada tahun 2010-2018, perubahan HRU yang paing dominan terjadi pada subDAS 3. Hal ini terjadi karena meningkatnya pertumbuhan pemukiman di daerah tersebut. Pemukiman meningkat sebesar $30 \%$ dalam periode 3-5 tahun sekali. Pada subDAS 1, luas pertanian lahan kering campur semak juga berkurang rentang tahun 2010-2018. Ini disebabkan karena meningkatkannya jumlah pembangunan yang mengubah lahan kering menjadi pemungkiman. Pada umumnya DAS Batang Arau bagian hulu dominannya adalah hutan hijau, hutan campur, dan sawah, dan lahan pertanian kering campur semak. Sedangkan pada daerah hilir dan muara didominasi oleh pemukiman dan transportasi.

\section{Analisis Debit Andalan}

Untuk menghitung debit andalan pada DAS BatangArau, digunakan tiga stasiun curah hujan yaitu stasiun Gunung Nago, Ladang Padi dan stasiun Bungus. Masing-masing menggunakan periode 10 tahun, data curah hujan yang digunakan yaitu curah hujan maksimum perlimabelas hari pada tahun 2009 sampai dengan tahun 2018. Sedangkan untuk permodelan debit pada SWAT dibutuhkan data curah hujan harian.

Selanjutnya, data yang dibutuhkan adalah data cuaca/temperatur, kelembaban udara, kecepatan angin, dan penyinaran matahari yang mana akan mempengaruhi kondisi hidrologi suatu DAS. Cuaca dapat diartikan sebagai keadaan atmosfer pada suatu saat dan sifatnya selalu berubahubah, sedangkan iklim dapat diartikan sebagai keadaan cuaca rata-rata dalam periode lama.

Analisis data yang dilakukan secara manual yaitu menghitung evapotranspirasi $\left(E T_{0}\right)$ dengan menggunakan metode Penman Modifikasi. Dengan rumus:

$E T_{0}=c \times[W \times R n+(1-W) \times f(U) \times$ $(e s-e a)(3)$

Lalu dilanjutkan dengan menghitung debit andalan menggunakan metode FJ Mock. Metode ini cocok digunakan untuk daerah 
yang memiliki curah hujan yang cukup tinggi seperti Sumatera Barat.

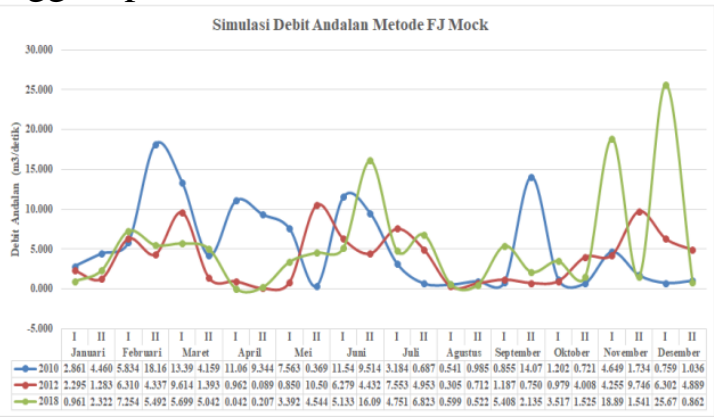

Gambar 12. Grafik simulasi debit andalan metode FJ. Mock

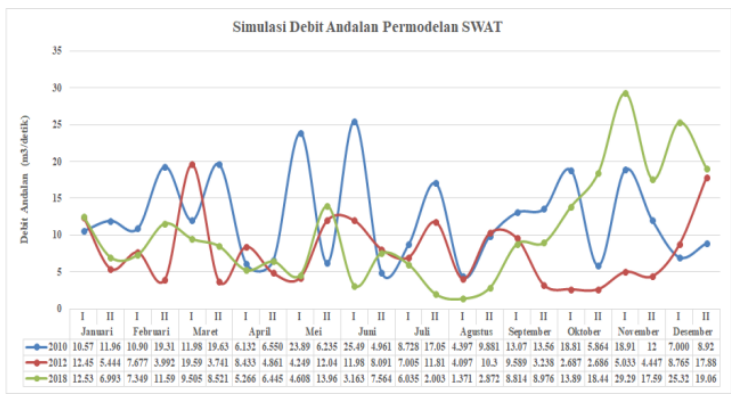

Gambar 13. Grafik simulasi debit andalan permodelan SWAT

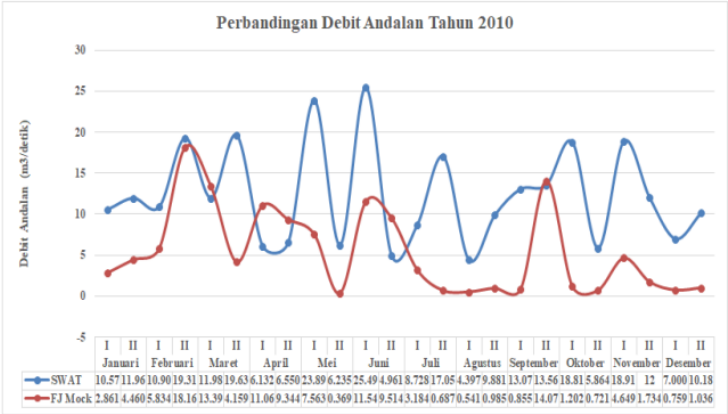

Gambar 14. Grafik perbandingan debit andalan metode FJ. Mock dengan SWAT tahun 2010

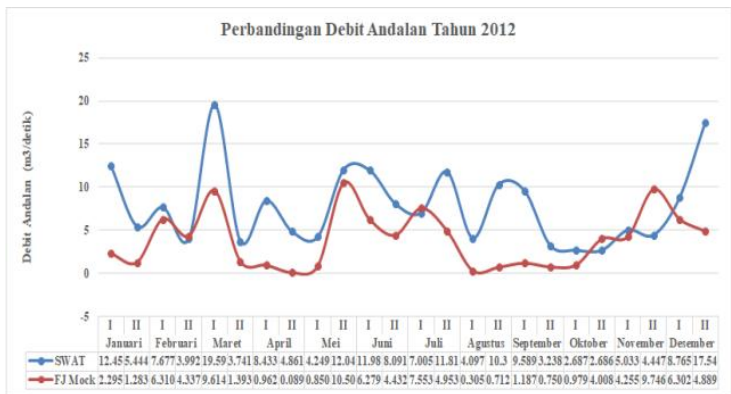

Gambar 15. Grafik perbandingan debit andalan metode FJ. Mock dengan SWAT tahun 2012

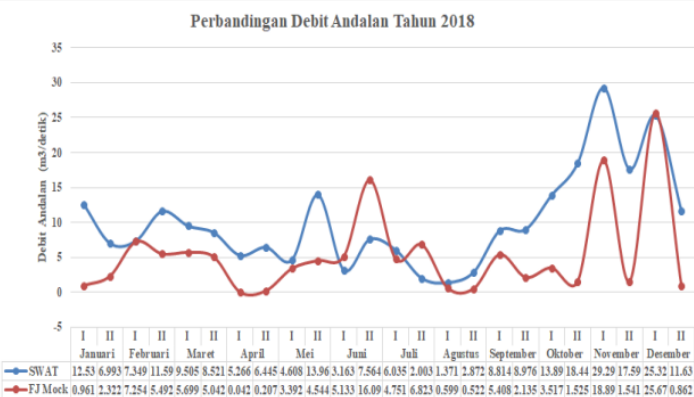

Gambar 16. Grafik perbandingan debit andalan metode FJ. Mock dengan SWAT tahun 2018

\section{SIMPULAN}

Berdasarkan tujuan dan hasil pembahasan dari penelitian yang telah dilakukan, dapat disimpulkan bahwa:

1. Perhitungan debit andalan dengan model SWAT dan Fj Mock diperlukan data DEM, tanah, tutupan lahan, Klimatologi, dan Curah Hujan. Pada tahun 2010-2018, perubahan jumlah dan luas HRU mempengaruhi akumulasi aliran permukaan dan debit andalan secara temporal. Hal ini disebabkan oleh koefisien runoff yang meningkat akibat perubahan penggunaan lahan pada DAS Batang Arau. Kenaikan koefisien setiap tahunnya bisa mencapai 0,1 .

2. Untuk sebaran penggunaan lahan, DAS Batang Arau didominasi oleh hutan lahan kering primer di bagian hulu. Sedangkan di daerah hilir berupa pertanian lahan kering, sawah, pemukiman, pertanian lahan kering campur semak, dan semak belukar rawa. Kawasan hutan lindung pada bagian hulu DAS memiliki persentase luas sebesar74.68\%.

3. Untuk Erosi pada tahun 2010 dan 2012 mengalami peningkatan, sedangkan pada tahun 2018 terjadi penurunan dikarenakan terjadinya pengaruh perubahan tutupan lahan pada DAS Batang Arau. Pada perhitungan erosi dengan menggunakan model SWAT dan USLE didapat erosi tertinggi berada pada subDAS 6 karena adanya pertambangan batu kapur. 


\section{DAFTAR PUSTAKA}

[1] Arnold JG, Kiniry JR, Srinivasan R, Williams JR, Haney EB, Neitsch SL. 2011. Soil and Water Assessment Tool : Input/Output File Documentation Version 2009. Texas: Agricultural Research Service and Texas AgriLife Research.

[2] Arsyad, S. 2000. Konservasi Tanah dan Air, Serial Pustaka, IPB Press , Bagian Proyek Penelitian Sumberdaya Agroklimat dan Hidrologi (BP2SAH) dan Bagian Proyek Pembinaan Perencanaan Sumber Air Ciliwung - Cisadane, 2004. Laporan Akhir Pengembangan Teknologi Dam Parit untuk Penanggulangan Banjir dan Kekeringan. Bogor: Balai Agroklimat dan Hidrologi Bogor.

[3] Asdak, Chay. 2004. Hidrologi dan Pengelolaan Daerah Aliran Sungai. Yogyakarta: Gadjah Mada University Press

[4] Emiyati. 2012. Hydrologic Response Unit (HRU) dan Debit Aliran Ci Rasea. Tesis. Depok: Universitas Indonesia.

[5] Firdaus, Gunadi. 2014. Analisis Respon Hidrologi Terhadap Penerapan Teknik Konservasi Tanah di Sub DAS Lengkong Menggunakan Model SWAT. Tesis. Bogor: Institut Pertanian Bogor

[6] Herdianto, R., Syofyan, E. R., \& Aguskamar. (2013). Pemanfaatan Informasi Topografi dan Indeks Vegetasi untuk Studi Dinamika Proses Hidrologi Daerah Aliran. Jurnal Ilmiah. POLI REKAYASA. Volume 8 Nomor 2, April 2013. ISSN : 1858-3709.
[7] Herdianto, R., Istijono, B., Syofyan, E. R., \& Dalrino.(2018). Investigation of Pangkalan Floods: Possible Reasons and Future Directions. International Journal on Advanced Science, Engineering and Information Technology, Vol.8 (2018) No. 6 , pp. 2510- 2515.

[8] Herdianto, R., Syofyan, E. R., Hanwar, S., Istijono, B., \& Dalrino. (2017). The Investigation of 1997 and 2015 El Nino Events in West Sumatera, Indonesia. International Journal on Advanced Science, Engineering and Information Technology, Vol. 7 (2017) No. 2, pp. 418-423.

[9] Naibaho, Melodi. 2017. Simulasi Model ArcSWAT Untuk Menganalisis Aliran Permukaan di DAS Anai Hulu. Skripsi. Padang: Universitas Andalas.

[10] Neitsch, S.L, J.G. Arnold, J.R. Kiniry, J.R. Williams. 2005. Soil and Water Assessment Tool Theoretical Documentation Version 2005. Texas: Agricultural Research Service and Texas Agricultural Experiment Station.

[11] Rahayu, S. dkk. 2009. Monitoring Air di Daerah Aliran Sungai. ICRAF Asia tenggara.

[12] Syofyan. E. R, Saidi, A., Istijono, B., \& Herdianto, R. (2017). Model Hidrograf Akibat Perubahan Tataguna Lahan DAS Batang Kuranji (Studi Kasus Sub DAS Danau Limau Manis). POLI REKAYASA Volume 13, Nomor 1, Oktober 2017.

[13] Syofyan. E. R, Saidi, A., Istijono, B., \& Herdianto, R. (2016). Kajian Model Hidrograf Akibat Perubahan Tataguna Lahan dengan 
Menggunakan Data Lapangan DAS

Batang Air Dingin . POLI

REKAYASA Volume 12, Nomor 1, Oktober 2016.

[14] Syofyan, E. R., Saidi, A., Istijono, B., Herdianto, R., (2018). The Hidrologic Impacts of Land Use Changes in the Middle and Upper Catchment. International Journal of Civil Engineering and Technology (IJCIET) 9 (11), 2018, pp. 997-1005.

[15] Syofyan, E. R., Saidi, A., Istijono, B., Herdianto, R., (2020). The Changes of Runoff with DEM Resolution. International Journal of Recent Technology and Engineering (IJRTE) ISSN: 2277-3878, Volume-8 Issue-6, March 2020. 